\title{
BMJ Open Characterising the evidence base for advanced clinical practice in the UK: a scoping review protocol
}

Catrin Evans (D , , Brenda Poku, ${ }^{1}$ Ruth Pearce, ${ }^{1}$ Jeanette Eldridge, ${ }^{1}$ Paul Hendrick, ${ }^{1}$ Roger Knaggs, ${ }^{2}$ John McLuskey, ${ }^{1}$ Philippa Tomczak, ${ }^{3}$ Ruaridh Thow, ${ }^{4}$ Peter Harris, ${ }^{5}$ Joy Conway, ${ }^{6}$ Richard Collier ${ }^{7}$

To cite: Evans C, Poku B, Pearce R, et al. Characterising the evidence base for advanced clinical practice in the UK: a scoping review protocol. BMJ Open 2020;10:e036192. doi:10.1136/ bmjopen-2019-036192

- Prepublication history and additional material for this paper are available online. To view these files, please visit the journal online (http://dx.doi. org/10.1136/bmjopen-2019036192).

Received 04 December 2019 Revised 25 February 2020 Accepted 02 April 2020

\section{Check for updates}

(c) Author(s) (or their employer(s)) 2020. Re-use permitted under CC BY-NC. No commercial re-use. See rights and permissions. Published by BMJ.

${ }^{1}$ School of Health Sciences, University of Nottingham,

Nottingham, UK

${ }^{2}$ School of Pharmacy, University of Nottingham, Nottingham, UK

${ }^{3}$ School of Sociology and Social Policy, University of Nottingham, Nottingham, UK

${ }^{4}$ Emergency Department, Nottingham University Hospitals NHS Trust, Nottingham, UK

${ }^{5}$ Health Education England East Midlands, Nottingham, UK ${ }^{6}$ College of Health and Life Sciences, Brunel University, Uxbridge, UK

${ }^{7}$ Health Education England, Leeds, UK

Correspondence to

Dr Catrin Evans;

catrin.evans@nottingham.ac.uk

\section{ABSTRACT}

Introduction A global health workforce crisis, coupled with ageing populations, wars and the rise of noncommunicable diseases is prompting all countries to consider the optimal skill mix within their health workforce. The development of advanced clinical practice (ACP) roles for existing non-medical cadres is one potential strategy that is being pursued. In the UK, National Health Service (NHS) workforce transformation programmes are actively promoting the development of ACP roles across a wide range of non-medical professions. These efforts are currently hampered by a high level of variation in ACP role development, deployment, nomenclature, definition, governance and educational preparation across the professions and across different settings. This scoping review aims to support a more consistent approach to workforce development in the UK, by identifying and mapping the current evidence base underpinning multiprofessional advanced level practice in the UK from a workforce, clinical, service and patient perspective.

Methods and analysis This scoping review is registered with the Open Science Framework (https://osf.io/tzpe5). The review will follow Joanna Briggs Institute guidance and involves a multidisciplinary and multiprofessional team, including a public representative. A wide range of electronic databases and grey literature sources will be searched from 2005 to the present. The review will include primary data from any relevant research, audit or evaluation studies. All review steps will involve two or more reviewers. Data extraction, charting and summary will be guided by a template derived from an established framework used internationally to evaluate ACP (the Participatory Evidence-Informed Patient-Centred ProcessPlus framework).

Dissemination The review will produce important new information on existing activity, outcomes, implementation challenges and key areas for future research around ACP in the UK, which, in the context of global workforce transformations, will be of international, as well as local, significance. The findings will be disseminated through professional and NHS bodies, employer organisations, conferences and research papers.

\section{INTRODUCTION}

\section{Rationale}

A global health workforce crisis, coupled with ageing populations, wars, escalating costs

\section{Strengths and limitations of this study}

- The review will provide a state-of-the-art picture of the evidence base (including outcomes and key implementation issues) for advanced clinical practice roles in the UK.

- The review will highlight key research gaps and research needs for workforce transformation around advanced clinical practice in the UK.

- Although the review has a UK focus, lessons learnt from this context will be of international interest, given that countries all over the world are engaged in similar workforce transformations through advanced health worker role development.

- The multiprofessional and multisectoral focus will enable important comparisons to be drawn across these dimensions, but may limit the potential for in-depth analysis of profession-specific or sectorspecific issues.

and the rise of non-communicable diseases is prompting all countries to consider the optimal skill mix within their health workforce. ${ }^{1-6}$ The development of advanced clinical practice roles for existing cadres is one potential strategy that is being pursued..$^{7-9}$ The origins of advanced clinical practice trace back to nursing in the USA and Canada in the mid-1960s, followed by the UK in the mid-1980s, then New Zealand and Australia in the 1990s. ${ }^{70}$ Advanced nurse practitioner roles evolved out of medical staff shortages, implementation of the European Working Time Directive (which reduced junior doctors' working hours in the UK), changing healthcare population needs and increased ambitions for professional status and clinical career progression. ${ }^{11}$ More recently, other health and care professions have also adopted advanced, extended and expanded clinical roles $^{12-17}$ and new non-medical cadres such as physician associates have been developed. ${ }^{18}$

In the UK, health has been a devolved responsibility of its four countries (England, 
Scotland, Wales and Northern Ireland) since the late 1990s and each country has its own 'National Health Service' (NHS). The NHS in each country is tax-funded services, providing universal health coverage, and, although some policy differences exist, they share many similar goals and challenges. ${ }^{19}$ Health services across the UK are actively exploring the development and implementation of new and advanced clinical roles to address workforce challenges and transform the way that services are delivered. ${ }^{20-25}$ For example, in England, an 'NHS Long Term Plan ${ }^{, 26}$ sets out a vision for healthcare for the next 10 years, which includes the development of new integrated systems of care that aim to cross traditional divides between health and social care sectors and related professional groups, and enable more efficient and innovative ways of working. ${ }^{27} 28 \mathrm{New}$ service models (referred to as 'Vanguards' in England and delivered through 'Sustainability and Transformation Partnerships') are taking a wide variety of forms. ${ }^{29}$ For example, some areas have integrated primary and acute care systems along with mental health services. Others have created multispeciality community care providers focused on providing better care and rehabilitation services for older people. ${ }^{28}$

Across the UK, plans have been developed to give an immediate focus on workforce actions required to implement such new models of care organisation and delivery. ${ }^{102630-32}$ These recognise the need to invest in the development of new roles and advanced skills to enable workforce expansion- to be achieved by developing experienced professionals practising to the full extent of their education and training. This recognition has a twofold purpose: experienced health and care professionals will be enabled to work across professional boundaries and take on an extended scope of practice thus addressing workforce needs while also providing career development and rewarding opportunities to improve retention. ${ }^{21}$

Advanced clinical practitioners (ACPs) are now being developed throughout the UK across a wide range of professional groups such as nursing, pharmacy, paramedicine, physiotherapy, radiotherapy, occupational therapy and others (see online supplementary file 1 for a list of professions/occupational groups that are being considered for the purposes of this review) ${ }^{33}$ Across the NHS, these occupational groups are collectively referred to as 'health and care professionals'. ${ }^{33} 34$ The term "care professional' does not denote a specific professional role, but rather, refers to the fact that certain professions or occupational groups may work within or across a range of settings and sectors in addition to more traditional health services, for example, within integrated care systems, in social care, in the private or voluntary sectors (eg, care homes) or in criminal justice settings. ${ }^{33}$

These UK-wide policy developments have brought to the forefront ongoing concerns around significant variations that exist in the definition, nomenclature, implementation, regulation and education of ACP roles across different professions and settings. In contrast to countries where there are clear routes for advanced practice education, credentialing and regulation, there is a recognition that in the UK, especially within nursing, there has historically been considerable and confusing variation in advanced level role titles, job descriptions and role profile. ${ }^{1235}$ One recent UK study, for example, found 595 different job titles that denote specialist and advanced nursing practice roles. Likewise, there is currently significant variation in educational preparation across roles and in the content of existing advanced clinical practice training programmes. ${ }^{35-37}$ This variability impedes workforce planning and raises concerns about patient safety. ${ }^{36}$

In order to address these issues in England, the workforce transformation agenda is being supported by a national non-departmental public body, 'Health Education England' (HEE). HEE's remit includes the education and training of individuals working at advanced levels through the development of advanced skills and educational training standards that can apply across a wide range of professional groups. ${ }^{26}$ In 2017, HEE published a Multi-professional Framework for Advanced Clinical Practice for England ${ }^{33}$ providing a definition of ACP stating that: 'Advanced clinical practice is delivered by experienced, registered health and care practitioners. It is a level of practice characterised by a high degree of autonomy and complex decision making. This is underpinned by a master's level award or equivalent that encompasses the four pillars of clinical practice, leadership and management, education and research, with demonstration of core capabilities and area specific clinical competence'. The release of the HEE ACP Framework aims to support the implementation of advanced level clinical practice in health and related environments in order to ensure that health and care practitioners are supported in their role. The framework provides a basis to align existing educational curricula and competence frameworks and aims to create greater consistency across advanced clinical practice as well as inform new developments. The HEE ACP framework currently includes 'consultant level' practice, a role in the NHS Career Framework representing a more senior level of practice and service leadership that encompasses but goes beyond ACP capabilities. ${ }^{38} 39$ Within NHS Career Frameworks, advanced practice roles are deemed to be at level 7, whereas consultant practice roles tend to be level 8 (where level 5 represents the starting point for newly registered practitioners). ${ }^{40}$

The HEE ACP framework applies specifically to England, but has been developed in consultation with stakeholders that represent professions across the UK (eg, Professional Bodies and Royal Colleges) and has drawn on similar advanced practice frameworks that exist in the other three countries. ${ }^{23-25}$

As recognised in the HEE and other ACP frameworks, it is proposed that ACPs are educated to masters level (or equivalent) and have developed the knowledge and skills to allow them to take on expanded roles and scope of practice caring for patients (HEE refers to "masters level' as an award that uses the relevant descriptors set at academic level 7 by the Framework for Higher Education 
Qualifications) ${ }^{33}{ }^{41}$ According to the HEE ACP framework, all health and care professionals working at an advanced level of practice should have developed their knowledge and skills to the level indicated in the core capabilities, across four pillars of advanced clinical practice: (1) clinical practice, (2) leadership and management, (3) education and (4) research. ${ }^{33}$ A key characteristic of professionals practising at an advanced level is the ability to work autonomously, thereby enhancing capacity and capability within multiprofessional teams. ACPs aim to improve clinical continuity, provide more patient-focused care and help to provide safe, accessible and high-quality care for patients. ${ }^{42}$

Across the UK, there are currently different ways to gain and develop advanced practice capabilities depending on the nature and scope of advanced health and care practitioners' practice. ${ }^{33}$ In England, for example, as part of HEE's drive to standardise advanced level practice, a national 'Centre for Advancing Practice' is being established. The Centre is a partnership between HEE and NHS England, NHS Improvement and other national stakeholders. The Centre's role is to strengthen governance arrangements for advanced level practice by recognising practitioners working at an advanced level through two routes: (1) accreditation of university education programmes, and (2) an equivalence recognition route. Individuals and health and care providers may access different routes to evidence achievement of advanced level capability and competence through accreditation or recognition of prior learning, work-based learning. ${ }^{3637}$

HEE is currently developing an approach to evaluate 'equivalence' that uses assessment processes established by the Academy of Health Care Science which defines equivalence as 'a methodological approach where the outcomes of two processes are directly comparable even though the paths to achieving them are different. When equivalence is shown to exist between a new qualification and the qualification or experience an individual already has, further education or training becomes unnecessary'. ${ }^{43}$ The process of determining equivalence is a subjective process based on an individual demonstrating appropriate mapping of their training, education and experiences to a set of predetermined standards-in this case, the ACP Framework standards and HEE's standards for the equivalence route. ${ }^{33}$ However, HEE's precise methodology and approach for assessing equivalence are currently still under development.

As this national work commences, there is an urgent need to understand more fully the current context of, and evidence around, ACP across the specialties, sectors and the multiprofessional workforce in different roles across different care pathways to inform a baseline understanding of the contribution and challenges of ACP in the health service. This proposed scoping review seeks to address this need by identifying and mapping the current evidence base around ACP in the four UK countries. This will enable a UK-wide as well as country-specific picture of the current evidence on ACP to be identified.

\section{Previous systematic reviews}

There have been several systematic reviews undertaken to determine the feasibility, impact and implementation challenges around ACP, specific to different professional groups. ${ }^{13-1644-64}$ These reviews show that, globally, there is good evidence (especially related to nursing) to suggest that ACPs practise safely and can achieve good patient outcomes and high patient satisfaction. Evidence on costeffectiveness and impact on service organisation/efficiency, however, remains equivocal. ${ }^{204665}$ Implementation challenges include poor role recognition, lack of support and lack of integration within the wider healthcare system. More evidence is needed on how to support, scale up and sustain ACP-related innovations ${ }^{6667}$ Most existing reviews have had an international focus making it hard to determine the applicability of their findings specifically to the UK NHS context, and to identify the key gaps in the evidence base that are specific to the UK context. In addition, the profession-specific focus of previous reviews limits the ability to conceptualise the evidence base for the ACP role on a more sector-specific or specialityspecific basis. Some reviews have been UK specific but have been restricted to consultant-level practice and to just one professional group. ${ }^{22} 3968$ In order to inform UK service-wide transformation, there is a pressing need to map out the existing UK evidence around ACP. In doing so, important areas for future research and development will be identified, which, in the context of global workforce transformations, will be of international, as well as local, significance. ${ }^{669-71}$

\section{Aim and objectives}

Aim

To establish the current evidence base underpinning multiprofessional advanced level practice from a workforce, clinical, patient and service perspective in the UK.

\section{Objectives}

1. To identify what evidence exists about implementation, impacts and outcomes of advanced clinical practice in the UK across (a) different professions, (b) different sectors and (c) different specialities.

2. To identify the challenges reported to affect advanced level practice implementation by sector, specialty and profession in the UK.

3. To identify and describe the different types of outcomes and impacts of advanced level practice roles that have been reported, and to summarise existing knowledge on these, by sector, specialty and profession in the UK.

4. To identify key gaps in the existing evidence base and the most urgent questions for future research.

5. To consider how advanced level practice is being defined, conceptualised and applied across professions and the public, private and voluntary sectors of service provision. 


\section{METHODOLOGY AND METHODS \\ Scoping review design}

This scoping review will follow a framework proposed by the Joanna Briggs Institute (JBI) ${ }^{72} 73$ which builds on previous guidance developed by Arksey and O'Malley ${ }^{74}$ and Levac et al. ${ }^{75}$ The JBI framework ${ }^{72}$ recommends organising the review process into nine stages:

1. Defining and aligning the review objectives and questions.

2. Developing and aligning the inclusion criteria with the objective and questions.

3. Describing the planned approach to evidence searching, selection, extraction and charting.

4. Searching for the evidence.

5. Selecting the evidence.

6. Extracting the evidence.

7. Charting the evidence.

8. Summarising the evidence in relation to the objectives and questions.

9. Consultation (throughout).

While the JBI framework ${ }^{72}$ informs the overall conduct of the scoping review, the 'Preferred Reporting Items for Systematic Reviews and Meta-Analyses (PRISMA) extension for Scoping Reviews ${ }^{76}$ has also been used to guide the reporting of this protocol, and will also subsequently be used to structure the reporting of the full review.

\section{Review registration}

This review title has been registered with Open Science Framework. $^{77}$

\section{Review team}

The review is being conducted by a team comprised of multiprofessional expert clinicians, academics and policymakers in the field of ACP (RT, RP, JC, RC, RK, JMcL, $\mathrm{PH}, \mathrm{PT}$ ), an information scientist (JE), a methodologist (CE) and a research fellow (BP). The team reflects multiprofessional expertise in nursing (CE, RP, BP, JMcL, RT), physiotherapy (JC, RC, PH), pharmacy (RK) and criminal justice work (PT).

\section{Patient and public involvement}

The review team also includes a senior lay representative within HEE (PRBH) who has been involved from the outset. He has helped to shape the review aims and objectives and will seek to ensure that the review makes patient and family concerns a key focus at every stage.

\section{Consultation}

As per JBI guidance, ${ }^{72}$ consultation is being built into the review from the outset. The ACP steering committee within HEE and professional bodies will be regularly consulted to help with (1) clarifying profession-specific nomenclature and operational definitions around ACP and (2) identifying key papers and grey literature. Towards the end of the review, there will be a national consultation event where the key findings are shared with invitees across all professions, sectors and specialities. Stakeholder views, including our public representative, will be sought to elucidate the context-specific significance of the findings and to help shape policy and practice-relevant recommendations.

\section{Eligibility criteria}

Constructing the eligibility criteria for inclusion of papers within this review has been highly challenging due to: (1) the broadness of the definition of ACP, (2) the varying interpretations of ACP across different professions, (3) the widely varying terminology of ACP-related roles and titles both within and across professions and (4) the wide range of professions and occupational groups involved. It is well recognised that achieving clarity and consistency around ACP is still a work in progress. Indeed, this review is one of multiple HEE-funded projects underway designed to promote clarity and stability within this area of workforce policy by establishing a system benchmark of the existing field of evidence. In particular, there are grey areas, overlaps and blurred boundaries between advanced and consultant-level practice and between advanced, extended, expanded and specialist practice. Within these grey areas, we have attempted to construct clear inclusion and exclusion criteria for the review, but recognise that these may be contested within particular professions, and, as per the iterative nature of scoping reviews, ${ }^{72} 7475$ may be slightly revised as the process gets underway and as consultation continues. The inclusion criteria set out in table 1 use and expand on the mnemonic described by JBI for question formulation for scoping reviews (population, concept, context). ${ }^{72}$

\section{Information sources}

The following bibliographic databases will be searched in the period October 2019-March 2020 using the date range of 1 January 2005 to the present:

- Medline (specific segment, Ovid Medline and Epub Ahead of Print, In-Process and Other Non-Indexed Citations, Daily and Versions), 1946 to current (updated daily).

- Health Management Information Consortium 1979 to present (updated bimonthly).

- Allied and Complementary Medicine on Ovid, 1985 to present (updated monthly).

- Embase on Ovid, 1980 to present (updated daily/ weekly).

- PsycINFO on Ovid, 1806 to present (updated weekly).

- Cumulative Index to Nursing and Allied Health Literature (CINAHL) Plus with Full Text on EBSCOhost, 1937 to current.

- SportDiscus on EBSCOhost, 1800 to current.

- Applied Social Sciences Index and Abstracts on ProQuest, 1987 to current.

- Occupational Therapy Systematic Evaluation of Evidence (OTseeker) (http://www.otseeker.com/).

- Physiotherapy Evidence Database (https://www. pedro.org.au/)

- The Cochrane Library. 
Table 1 Inclusion and exclusion criteria

Inclusion criteria
Population:
All health and care professions
within the NHS and related
environments, for example,
local authority, criminal justice,
NHS commissioned voluntary
and private services.

Concept:

Implementation of advanced

level practice

\section{Rationale for inclusion and exclusion}

The HEE definition of ACP is for all health and care related professions currently recognised as potentially able to become ACPs. This is deliberately broad as a key aim of the review is to establish the nature of evidence that exists in the UK on advanced level practice.

See online supplementary file 1 for a full list of professions and occupational groups included in this review. It is important to note, however, that the list in online supplementary file 1 does not represent a final definitive list of all professions/occupational groups that are eligible for ACP recognition. As noted above, the criteria, definition and scope of ACP within different groups is a contested and shifting area of healthcare policy in the UK. Hence, the list represents a 'work in progress' of HEE's considerations on the issue at the time of this particular review.

The HEE definition conceptualises advanced clinical practice as a level of practice rather than as a specific role. ${ }^{33}$ Hence, the review uses the HEE definition as a starting point to determine eligibility of a paper, but recognises historical and profession-specific variation in how the definition may be interpreted (and how it may have been described in the past prior to the 2017 HEE definition). For the purpose of this review, advanced clinical practice will include consultant level practice (this is a role in the NHS representing a more senior level of practice and service leadership that encompasses but goes beyond ACP capabilities). ${ }^{38}$

${ }^{39}$ Where other terms and titles are used, papers will be scrutinised to establish whether or not the role being described meets the characteristics of advanced clinical practice set out in the HEE definition. For example, common roles that will need scrutiny on a paper-by-paper basis include roles that are referred to as 'extended scope', 'expanded', 'specialist practice', 'prescribing' or 'practitioner' roles (see online supplementary file 2 for the full search strategy where we have attempted to elaborate all possible synonyms for advanced level practice roles across all professions).

This review will include papers that report on the implementation of advanced level practice roles. It will not include papers that report on issues around the initial educational preparation related to advanced clinical practice. This has been addressed in a recent systematic review ${ }^{37}$ and is also a key area of enquiry within a separate HEE-funded project. However, the scoping review will, for example, include papers that report on further educational or training issues for practitioners who are already working in advanced level roles-if these are mentioned in relation to role implementation challenges.

We will include papers that report empirical data on the views, outcomes and experiences related to advanced clinical practice roles that are being, or have been, implemented. We will not include opinion pieces or papers that report stakeholder views of potential new ACP roles or services (ie, where they do not report actual experience of a role).

\section{Context:}

Country:

UK-England, Scotland, Wales

and Northern Ireland

Sector:

Health and related environments, for example, local authority (social care), criminal justice, NHS commissioned voluntary and private services. Specialty:

any

\section{Language:}

English

This review has been commissioned to inform policy for the NHS in England. However, due to the similarities in health service context and ACP role development across the UK countries, the review will include evidence from all UK countries. We will not include evidence from any other countries however. We argue that where reviews are designed to be highly policy relevant and context specific, a single rather than multicontext focus is appropriate. ${ }^{91} 92$ In addition, the UK NHS services have unique structures, roles and processes which may make transferability of findings from other health system contexts problematic. However, international studies that include relevant evidence from the UK (provided that is it separately reported) would be included.

This is deliberately broad as a key aim of the review is to establish the nature of evidence that exists in the UK on advanced level practice.

This is deliberately broad as a key aim of the review is to establish the nature of evidence that exists in the UK on advanced level practice.

Date range:

2005-present

Only papers retrieved as English-language records (literature database records or full-text articles in English) will be included.

The rationale for the date limit of 2005 is due to the timing of key policy developments around advanced clinical practice. Prior to this date, most advanced clinical practice roles and research were limited to nursing and referred to a wide range of highly inconsistent titles, educational preparation, role definitions and scope of practice. ${ }^{12}$ In 2005, the Department of Health published an evaluation of extended formulary independent prescribing for nurses and this was a precursor to further policy publications around advanced roles, particularly related to nursing. ${ }^{93}$ In 2006 , the Department of Health published 'Modernising Nursing Careers: Setting the Direction' that identified the changes in healthcare delivery and structure and the need for nurses to advance their skills in a more formalised way. ${ }^{94}$ The work from this document first outlined the four pillars of advanced clinical practice which later were adopted into a Scottish Government Toolkit. ${ }^{95}$ This toolkit initially focused on advanced nursing practice but it supported ongoing development to enhance understanding of the role across other health and care professionals and across the four pillars of advanced clinical practice. From an allied health professional perspective, in 2006 a systematic review was conducted that established an agenda for extended role development for AHPs. ${ }^{13}$ Literature from 2006 onwards may include reference to AHPs working at an advanced level of practice. Similarly, within pharmacy, an 'Advanced and Consultant Level Framework' was developed in 2004 and has since been validated across pharmacy at all levels of practice. ${ }^{9697}$ This work informed the Royal Pharmaceutical Society publication Advanced Pharmacy Framework published originally in 2010, updated $2013 .^{96}$

Continued 
Table 1 Continued

\section{Inclusion criteria}

Types of evidence to be included:

Published papers or published conference abstracts reporting empirical data from primary research or service evaluations. Grey literature.

\section{Rationale for inclusion and exclusion}

We will include any study design. Grey literature may include doctoral theses or unpublished research or evaluation reports (however, in order to maintain quality, the latter will be included only if they provide detail of how the data were produced and are linked to an established registered body - for example, a university, an NHS or other governmental organisation or a registered non-governmental organisation). ${ }^{98}$ Reference lists of relevant systematic reviews will be searched for UK-focused studies.

ACP, advanced clinical practice; AHP, allied health profession; HEE, Health Education England; NHS, National Health Service.

- JBI Evidence Based Practice (EBP) database on Ovid (name changed to 'JBI Evidence Synthesis' from January 2020).

Grey literature, including theses repositories and some web-based discipline-specific research report collections, will also be searched (search strategies will be adapted accordingly for the discipline-focused resources):

- ProQuest Dissertations \& Theses A\&I, 1743 to current.

- Dietetics/nutrition (https://www.pennutrition.com/ index.aspx)

- Osteopathic research (http://www.osteopathicresearch.com/).

- Osteopathic medicine (https://ostemed-dr. contentdm.oclc.org/).

- Ambulance research (paramedics) (https://amber. openrepository.com/discover).

- Speech Pathology Database for Best Interventions and Treatment Efficacy (https://speechbite.com/).

The search strategies have been developed by an experienced research information specialist (JE) and refined through team discussion and identification of disciplinespecific terminology from health services organisations and associations such as:

- The NHS HEE Health Careers website (https://www. healthcareers.nhs.uk/ explore-roles/allied-healthprofessionals / roles-allied-health-professions).

- The Northern Ireland DoH Allied Health Professional Groups (https://www.health-ni.gov.uk/articles/introduction-allied-health-professionals-ahps).

- The NHS Scotland list of Healthcare Support Workers-AHP and Nursing Support Staff (http:// www. knowledge.scot.nhs.uk/hcsw/professionalcommunities.aspx).

- The NHS Wales list of allied health professionals (http://www.weds.wales.nhs.uk/ allied-health-professionals).

- The Health and Care Professions Council (https:// www.hcpc-uk.org/about-us / who-we-regulate / the-professions/).

In addition, relevant professional associations and society websites have been scrutinised to identify relevant terminology to include for each of the professions identified by HEE for inclusion.

In the course of researching the terminology and indexing relevant for each of these specific roles, an example of an existing search filter, for paramedics, was identified $^{78}$ :

"Ambulances.sh OR Emergency Medical Technicians. sh OR Air Ambulances.sh

OR paramedic*.tw OR ems.tw OR emt.tw OR prehospital.tw OR pre-hospital.tw

OR first responder*.tw OR emergency medical technicians.tw OR emergency services.tw OR Ambulance*.tw OR HEMS.tw OR field triage.tw"

This filter, which the paper states as being optimised for specificity, was used as a template, with some modifications, to develop parallel search statements for the other roles.

Online supplementary file 2 is annotated to show the different search statements developed for each professional group; these will be combined with search statements devised to retrieve terms relating to 'advanced practice' and its synonyms. The final answer sets, after limiting to UK-focused studies and to the date range from 1 January 2005 to present, will be imported to an EndNote library and duplicates across the different database searches identified and removed.

\section{Search limits and exclusions}

Several discipline-specific strategies include abbreviations for the role titles, which also apply in other contexts, and therefore statements required modification with excluded phrases to avoid high selectivity at the expense of the required specificity.

Indexing, as initially explored in Medline, ideally allows the use of terms for both the discipline (eg, occupational therapy) and the role (eg, occupational therapists), to ensure a full retrieval of relevant papers. However, this is not consistently available, either within a single database (eg, only "Podiatry" is available as a Medical Subject Heading (MeSH) term for chiropody/podiatry, no terms appear to be established currently for the corresponding roles), or across databases (eg, for dietitian or dietetics, the MeSH preferred terms in Medline are Nutritionists and Nutritional Sciences, respectively; in CINAHL, the terms are Dietitians and Dietetics, respectively).

In order to limit retrieved studies to those conducted in the UK, published UK-specific search filters (with some modifications) will be applied. ${ }^{79} 80$ The terms "National Health Service" or "NHS" are included as proxies for UK 
terms. See this section of the strategy in online supplementary file 2 for further details.

\section{Selection of sources of evidence}

All the identified citation records from the information search will be exported into EndNote V.X8 and duplicates will be removed. Titles and abstracts of the remaining citation records will be screened for inclusion against the inclusion criteria for the review. Full-text articles of records that appear to meet the inclusion criteria will be retrieved and screened against the inclusion criteria, and those that fulfil all the inclusion criteria will be included in the review. All the above steps will be conducted by two reviewers (BP and $\mathrm{CE}$ ) working independently at first and then meeting to compare the results and reach agreement. Any discrepancies will be resolved through consensus and consultation with the review team, and, where agreement cannot be reached, with key professional leads in the UK. Studies not meeting the inclusion criteria will be excluded. Reasons for exclusion will be provided in an Appendix in the final review report. The final search results will be reported in a PRISMA flow diagram. ${ }^{81}$ Authors of articles will also be consulted for additional information where necessary during the study selection process.

\section{Data charting process and data items}

Extraction and charting of study characteristics and study findings will be guided by the 'Participatory EvidenceInformed Patient-Centred Process-Plus' (PEPPA-Plus) framework. ${ }^{67} 82$ This framework provides a broad, yet comprehensive approach for advanced clinical practice role evaluation. The framework was initially developed in $2004^{67}$ and, since then, has been used to evaluate advanced practice implementation and outcomes in a wide range of international contexts and in a wide variety of settings. ${ }^{8283}$ To date, it has been mainly used within the nursing profession as this profession has a long history of advanced level practice role implementation. On careful review and consultation, the review team feel that the main domains within this framework are not profession specific and hence it would be suitable for the current project. Using an established framework for the review, will, we hope, enable a more straightforward comparison with international evidence on ACP and will also facilitate benchmarking of any future evaluation research on ACP (assuming that such evaluations will collect data in the same or similar domains).

The PEPPA-Plus framework draws on the work of Donabedian $^{84}$ and includes information on three domains (structure, process and outcomes) related to ACP roles. In terms of structure, the framework includes information about important structural factors that affect ACP role implementation (eg, title, remuneration, regulatory and governance frameworks, educational preparation, stage of role implementation, setting, years of experience). In terms of process, the framework explores factors such as the tasks and activities undertaken by the ACP, the frequency and intensity of ACP/ patient interactions (the 'dose effect ${ }^{\prime 66}$ ) and the barriers and facilitators to role implementation. In terms of outcomes, these are explored in relation to five categories (each of which has several subcategories, and two of which have sub-sub categories): (1) patient and family (includes health status, health behaviours and perceptions of care and healthcare experiences); (2) quality of care (includes patient safety, processes of care and access to care); (3) healthcare provider, team and stakeholder (includes healthcare team performance, knowledge and skills, acceptance and satisfaction with the ACP role, ACP role support, job satisfaction); (4) organisation (includes recruitment and retention) and (5) healthcare use and costs (includes length of stay, readmission rates, waiting times, cost avoidance and cost savings). New data items not included within the framework may be identified and incorporated as the review progresses. This iterative approach is consistent with scoping review guidance ${ }^{72} 7475$ and also with established approaches to using a framework approach in evidence synthesis. ${ }^{85}$

Extraction of data on study characteristics and study findings will be managed in two different ways. Data on study characteristics (including information relating to the 'structural' domains of the PEPPA-Plus framework) will be extracted using a template which has been developed through consultations held by the research team and which will be analysed using an Excel spreadsheet. As noted above, this template may be refined through future consultations. Authors of studies will be contacted to obtain missing data where necessary and possible. Full details of the study characteristics template are provided in online supplementary file 3 .

Data relating to study findings will be managed using NVIVO. PDF copies of all included papers will be imported into NVIVO (V.12 Pro $^{86}$ ) software. Study findings will be coded against the key process and outcome domains specified in the PEPPA-Plus framework. ${ }^{82}{ }^{83}$ Full details of this initial set of process and outcome categories and subcategories are provided in online supplementary file 4 .

Charting and extraction will primarily be undertaken by one researcher (BP), although other team members may also be involved depending on the volume of papers that are eventually retrieved. This is a relatively common approach in scoping reviews and is considered appropriate as the focus is on extracting data for descriptive summary rather than to generate numerical estimates of effectiveness. ${ }^{8788}$ Nonetheless, strict attention will be paid to ensuring consistency and quality. This will be achieved in the following ways: (1) initially, BP and CE will independently chart/extract data from an initial set of 10 papers using different study designs and compare results. This will be done in order to develop a clear and unambiguous understanding of the meaning of each category/ subcategory within the data extraction templates and of how differently reported data items would be categorised; (2) this will be followed by another round of independent data extraction, comparison and discussion by $\mathrm{CE}$ 
and BP for another group of five papers (this process will continue until the team is satisfied that clear and shared understandings and a consistent approach have been achieved). In order to ensure transparency and rigour, this quality assurance process will include taking detailed notes of any areas of discrepancies or ambiguities and how they were resolved; (3) BP then will proceed to chart/extract data from the remaining papers; however, $\mathrm{CE}$ will read all the papers, check the accuracy of coding and identify any other issues that may need clarification; (4) finally, throughout the process, there will be weekly team meetings during which any ambiguous items or other issues are discussed and a way forward agreed. If other team members become involved in data charting/ extraction, the training and quality checking process described above will be repeated.

\section{Critical appraisal of individual sources of evidence}

As a scoping review, the purpose is to map out the existing evidence and to summarise key study findings within different domains rather than to evaluate the quality of individual studies to determine risk of bias related to particular outcomes. Hence, in line with the review aim of providing an overview of the existing evidence base, rather than undertake a formal quality assessment of each study, we will assign a 'level of evidence' rating to each study using JBI's well-established categorisation. ${ }^{89}$ In this way, it will be possible to evaluate the type of research that has been undertaken in terms of established evidence hierarchies, and, accordingly, to provide a commentary on the relative rigour of the existing evidence base.

\section{Synthesis of results}

Findings will be summarised and presented as per the main domains of the data extraction templates, configured in such a way as to address the key review objectives. Data relating to study characteristics will mainly be presented as a descriptive numerical summary accompanied by an explanatory narrative ${ }^{75}$ (eg, the percentage of studies that have been undertaken within different professions). Likewise, data related to study findings will be mapped within the categories of the PEPPA-Plus framework ${ }^{83}$ and will be reported as a narrative summary. ${ }^{90}$ Findings will be presented to explore sector-specific, specialityspecific and profession-specific commonalities and differences. Where possible, findings will be presented in tables or using concept network maps to provide a visual representation.

\section{Dissemination}

The scoping review results will be disseminated in three ways: (1) submission of a policy report to HEE, (2) publication in peer-reviewed journals (it is envisaged that at least two publications will be developed-one focused on primary care and one on acute care) and (3) presentation at HEE and national/international conferences.

\section{CONCLUSION}

This scoping review will provide comprehensive information on the body of research that exists on advanced clinical practice in the UK, spanning design, introduction, implementation and evaluation. Accordingly, it will be possible to map out the evidence on the impact of advanced clinical practice role and services on patient and families, healthcare providers and stakeholders, healthcare utilisation and cost, and quality of care. In addition, it will be possible to highlight the barriers and facilitators of the introduction and implementation of advanced clinical practice roles and services across different health and health-related sectors. Moreover, it will be possible to emphasise some of the organisational, professional and workforce issues associated with advanced clinical practice. Conversely, it will show areas that have been underresearched and may require further investigation and evaluation. This review will make an important contribution to policy development around ACP in the UK, and, in doing so, will highlight issue of wider interest to the international community working in this field. ${ }^{68}$

\section{Twitter Catrin Evans @Catrin_notts}

Contributors CE: coordinated and conceptualised the project; developed all aspects of the project methodology and manuscript. BP: drafted the Methods section of the manuscript and reviewed and commented on the whole manuscript. RP: drafted the Background section; reviewed and commented on the whole manuscript. JE: developed the search strategy; reviewed and commented on the manuscript. PaH, RK, JM, RT, and PeH: reviewed and commented on the manuscript. PT: reviewed and commented on the manuscript; developed implications for non-traditional healthcare settings. JC and RC: contributed to conceptualising the project; reviewed and commented on the manuscript.

Funding This work was supported by Health Education England (DN384826Evaluation for HEE ACP Programme-Current Evidence Based for Advanced Level Practice within Health and Related Environments).

Competing interests RP is a committee member of the Association of Advanced Practice Educators-UK (AAPE-UK) and represents AAPE-UK on the Health Education England (HEE) ACP Steering Group. RC is Clinical Lead for Musculoskeletal Practitioners in Primary Care \& Project Director for the Centre for Advancing Practice, Health Education England. JC is a Research Advisor to Health Education England.

Patient and public involvement Patients and/or the public were involved in the design, or conduct, or reporting, or dissemination plans of this research. Refer to the Methods section for further details.

Patient consent for publication Not required.

Provenance and peer review Not commissioned; externally peer reviewed.

Open access This is an open access article distributed in accordance with the Creative Commons Attribution Non Commercial (CC BY-NC 4.0) license, which permits others to distribute, remix, adapt, build upon this work non-commercially, and license their derivative works on different terms, provided the original work is properly cited, appropriate credit is given, any changes made indicated, and the use is non-commercial. See: http://creativecommons.org/licenses/by-nc/4.0/.

ORCID iD

Catrin Evans http://orcid.org/0000-0002-5338-2191

\section{REFERENCES}

1 Buchan J, Campbell J. Challenges posed by the global crisis in the health workforce. BMJ 2013;347:f6201.

2 Salsberg E, Quigley L. Achieving sustainable and appropriately trained health and social care workers for ageing populations. 
In: Health employment and economic growth: an evidence base. Geneva: World Health Organisation, 2017.

3 WHO. Task shifting: rational redistribution of tasks among health workforce teams. global recommendations and guidelines. Geneva: World Health Organisation, 2008.

4 The Lancet. 2020: unleashing the full potential of nursing. Lancet 2019;394:1879.

5 Freund T, Everett C, Griffiths P, et al. Skill mix, roles and remuneration in the primary care workforce: who are the healthcare professionals in the primary care teams across the world? Int $J$ Nurs Stud 2015;52:727-43

6 World Health Organisation. Global strategy on human resources for health: workforce 2030, 2016. Available: https://apps.who.int/ iris/bitstream/handle/10665/250368/9789241511131-eng.pdf; isessionid=12450DBCC25126832451660AF4F7F6BB? sequence $=1$ [Accessed 13 Feb 2020].

7 Leary A, MacLaine K. The evolution of advanced nursing practice: past, present and future. Nurs Times 2019;115:18-19.

8 de Bont A, van Exel J, Coretti S, et al. Reconfiguring health workforce: a case-based comparative study explaining the increasingly diverse professional roles in Europe. BMC Health Serv Res 2016;16:637.

9 Frenk J, Chen L, Bhutta ZA, et al. Health professionals for a new century: transforming education to strengthen health systems in an interdependent world. The Lancet 2010;376:1923-58.

10 England NHS. The NHS long term plan. London: NHS England, 2019

11 Currie G, Finn R, Martin G. Professional competition and modernizing the clinical workforce in the NHS. Work, Employment and Society 2009;23:267-84.

12 Leary A, Maclaine K, Trevatt P, et al. Variation in job titles within the nursing workforce. J Clin Nurs 2017;26:4945-50.

13 McPherson K, Kersten P, George S, et al. A systematic review of evidence about extended roles for allied health professionals. $J$ Health Serv Res Policy 2006;11:240-7.

14 Saxon RL, Gray MA, Oprescu FI. Extended roles for allied health professionals: an updated systematic review of the evidence. $J$ Multidiscip Healthc 2014;7:479-88.

15 Desmeules F, Roy J-S, MacDermid JC, et al. Advanced practice physiotherapy in patients with musculoskeletal disorders: a systematic review. BMC Musculoskelet Disord 2012;13:107.

16 Turner J, Coster J, Chambers D, et al. What evidence is there on the effectiveness of different models of delivering urgent care? a rapid review. Health Serv Deliv Res 2015;3:1-134.

17 Imison C, Castle-Clarke S, Watson R. Reshaping the workforce to deliver the care patients need (research report. London: Nuffield Trust, 2016

18 Nelson PA, Bradley F, Martindale A-M, et al. Skill-mix change in general practice: a qualitative comparison of three 'new' non-medical roles in English primary care. Br J Gen Pract 2019;69:e489-98.

19 Bevan G, Karanikolos M, Exley J, et al. The four health systems of the United Kingdom: how do they compare? : The Health Foundation and Nuffield Trust, 2014. Available: https://www.nuffieldtrust.org.uk/ files/2017-01/4-countries-report-web-final.pdf [Accessed 13 Feb 2020].

20 Bienkowska-Gibbs T, King S, Saunders C, et al. New organisational models of primary care to meet the future needs of the NHS: a brief overview of recent reports. London: RAND Europe, 2015.

21 Gilburt H. Supporting integration through new roles and working across boundaries. London: King's Fund, 2016.

22 Pierce E, Beling R. Advanced practitioner roles: relevance and sustainability in a 'liberated' NHS. IPDJ 2011;1:6.

23 Department of Health Social Services and Public Safety (Northern Ireland). Advanced nursing practice framework: supporting advanced nursing practice in health and social care trusts, 2016. Available: https://www.health-ni.gov.uk/sites/default/files/publications/health/ advanced-nursing-practice-framework.pdf [Accessed 13 Feb 2020].

24 NHS Education for Scotland. Advanced practice toolkit. Available: http://www.advancedpractice.scot.nhs.uk/ [Accessed 13 Feb 2020].

25 NHS Wales. Framework for advanced nursing, midwifery and allied health professional practice in Wales: National leadership and innovation agency for healthcare. Available: https://www.wales.nhs. uk/sitesplus/documents/829/NLIAH\%20Advanced\%20Practice\% 20Framework.pdf [Accessed 13 Feb 2020].

26 NHS England. Interim NHS people plan. London: NHS England, 2019.

27 NHS Health Education England. Integrated care. Available: https:// www.hee.nhs.uk/our-work/integrated-care\#skip-link

28 NHS England. New care models: Vanguards - developing a blueprint for the future of NHS and care services, 2016. Available: https:// www.england.nhs.uk/wp-content/uploads/2015/11/new care models.pdf [Accessed 13 Feb 2020].
29 NHS England. Integrated Care Systems. Available: https://www. england.nhs.uk/integratedcare/integrated-care-systems/ [Accessed 19 Feb 2020].

30 Scottish Government. Health and social care delivery plan, 2016. Available: https://www.gov.scot/binaries/content/documents/ govscot/publications/strategy-plan/2016/12/health-social-caredelivery-plan/documents/00511950-pdf/00511950-pdf/govscot\% 3Adocument/00511950.pdf[Accessed 13 Feb 2020].

31 NHS Wales. NHS Wales Planning Framework 2020/3, 2020. Available: https://gov.wales/sites/default/files/publications/2019-09/ nhs-wales-planning-framework-2020-to-2023.pdf[Accessed 13 Feb 2020].

32 Department of Health (Northern Ireland). Health and well being 2026: delivering together, 2019. Available: https://www.health-ni.gov.uk/ sites/default/files/publications/health/progress-report-full-document. pdf [Accessed 13 Feb 2020].

33 England HE. Multi-professional framework for advanced clinical practice in England. London: Health Education England, 2017.

34 British Association for Social Work England. Advanced Social Worker: Professional Capabilities Framework. Available: https:// www.basw.co.uk/system/files/resources/pcf-adv-social-worker.pdf [Accessed 19 Feb 2020].

35 East L, Knowles K, Pettman M, et al. Advanced level nursing in England: organisational challenges and opportunities. J Nurs Manag 2015;23:1011-9.

36 Council of Deans for Health. Advanced clinical practice education in England: event report from the 2018 Council of deans of Health/ Health education England advanced clinical practice education conference. London: Council of Deans for Health, 2018.

37 Dover N, Lee GA, Raleigh M, et al. A rapid review of educational preparedness of advanced clinical practitioners. J Adv Nurs 2019;75:3210-8

38 Scottish Government. Consultant nurses, midwives and allied health professions (NMAHPs): guidance for NHS boards, 2010 Available: http://www.advancedpractice.scot.nhs.uk/media/618/sgconsultants-guidance-march10.pdf] [Accessed 13 Feb 2020].

39 Kennedy F, McDonnell A, Gerrish K, et al. Evaluation of the impact of nurse consultant roles in the United Kingdom: a mixed method systematic literature review. J Adv Nurs 2012;68:721-42.

40 Skills for Health. NHS career framework. Available: https://www. skillsforhealth.org.uk/index.php?option=com_mtree\&task=att download\&link_id=163\&cf_id=24 [Accessed 19 Feb 2020].

41 Quality Assurance Agency. Uk quality code for higher education: Part A: setting and maintaining academic standards: the frameworks for higher education qualifications of UK degree Awarding bodies, 2014. Available: https://www.qaa.ac.uk/docs/qaa/quality-code/ qualifications-frameworks.pdf [Accessed 13 Feb 2020].

42 NHS Employers. Advanced clinical practice, 2019. Available: https:// www.nhsemployers.org/your-workforce/plan/workforce-supply/ education-and-training/advanced-clinical-practice [Accessed $01 \mathrm{Nov}$ 2019].

43 Academy for Healthcare Science. Equivalence. Available: https:// www.ahcs.ac.uk/equivalence/about-equivalence/what-isequivalence/[Accessed $13 \mathrm{Feb} 2020]$

44 Bentley M, Stirling C, Robinson A, et al. The nurse practitioner-client therapeutic encounter: an integrative review of interaction in aged and primary care settings. J Adv Nurs 2016;72:1991-2002.

45 Bigham BL, Kennedy SM, Drennan I, et al. Expanding paramedic scope of practice in the community: a systematic review of the literature. Prehosp Emerg Care 2013;17:361-72.

46 Bonsall K, Cheater FM. What is the impact of advanced primary care nursing roles on patients, nurses and their colleagues? A literature review. Int J Nurs Stud 2008;45:1090-102.

47 Cardwell K, Smith SM. Clinical pharmacists working within family practice: what is the evidence? Fam Pract 2018;35:120-1.

48 Casey M, O'Connor L, Cashin A, et al. An overview of the outcomes and impact of specialist and advanced nursing and midwifery practice, on quality of care, cost and access to services: a narrative review. Nurse Educ Today 2017;56:35-40.

49 Cohen V, Jellinek SP, Hatch A, et al. Effect of clinical pharmacists on care in the emergency department: a systematic review. Am J Health Syst Pharm 2009;66:1353-61.

50 Donald F, Martin-Misener R, Carter N, et al. A systematic review of the effectiveness of advanced practice nurses in long-term care. $J$ Adv Nurs 2013;69:2148-61.

51 Evans R, McGovern R, Birch J, et al. Which extended paramedic skills are making an impact in emergency care and can be related to the UK paramedic system? A systematic review of the literature. Emerg Med J 2014;31:594-603.

52 Ferreira GE, Traeger AC, O'Keeffe M, et al. Staff and patients have mostly positive perceptions of physiotherapists working 
in emergency departments: a systematic review. J Physiother 2018;64:229-36.

53 Hardy M, Johnson L, Sharples $\mathrm{R}$, et al. Does radiography advanced practice improve patient outcomes and health service quality? A systematic review. Br J Radiol 2016;89:20151066-1062.

54 Harrison-Blount M, Nester C, Williams A. The changing landscape of professional practice in podiatry, lessons to be learned from other professions about the barriers to change - a narrative review. J Foot Ankle Res 2019;12:23.

55 Jakimowicz M, Williams D, Stankiewicz G. A systematic review of experiences of advanced practice nursing in general practice. BMC Nurs 2017;16:6.

56 Jebara T, Cunningham S, MacLure K, et al. Stakeholders' views and experiences of pharmacist prescribing: a systematic review. $\mathrm{Br} J$ Clin Pharmacol 2018;84:1883-905.

57 Jokiniemi K, Pietilä A-M, Kylmä J, et al. Advanced nursing roles: a systematic review. Nurs Health Sci 2012;14:421-31.

58 Kanda M, Ota E, Fukuda H, et al. Effectiveness of community-based health services by nurse practitioners: protocol for a systematic review and meta-analysis. BMJ Open 2015;5:e006670.

59 Kersten P, McPherson K, Lattimer V, et al. Physiotherapy extended scope of practice - who is doing what and why? Physiotherapy 2007:93:235-42.

60 Moran GM, Nairn S. How does role transition affect the experience of trainee advanced clinical practitioners: qualitative evidence synthesis. J Adv Nurs 2018;74:251-62.

61 NA-Ohoo S, Cortinovis T, Green C, et al. Introducing novel advanced practice roles into the health workforce: dietitians leading in gastrostomy management: advanced practice roles in gastrostomy management. Nutr Diet 2018;76.

62 Thom SE. Does advanced practice in radiography benefit the healthcare system? A literature review. Radiography 2018;24:84-9.

63 Thompson J, Yoward S, Dawson P. The role of physiotherapy extended scope practitioners in musculoskeletal care with focus on decision making and clinical outcomes: a systematic review of quantitative and qualitative research. Musculoskeletal Care 2017;15:91-103.

64 Williams K. Advanced practitioners in emergency care: a literature review. Emerg Nurse 2017;25:36-41.

65 Tsiachristas A, Wallenburg I, Bond CM, et al. Costs and effects of new professional roles: evidence from a literature review. Health Policy 2015;119:1176-87.

66 Brooten D, Youngblut JM, Deosires W, et al. Global considerations in measuring effectiveness of advanced practice nurses. Int $J$ Nurs Stud 2012;49:906-12.

67 Bryant-Lukosius D, Dicenso A. A framework for the introduction and evaluation of advanced practice nursing roles. J Adv Nurs 2004;48:530-40.

68 Hourahane G, West N, Barnes R, et al. Supporting trail-blazing: a systematic review of the factors that facilitate or inhibit the implementation of new nursing roles: the experiences of UK consultant nurses. JBI Libr Syst Rev 2012;10:3146-294.

69 Jones A, Powell T, Watkins D, et al. Realising their potential? exploring interprofessional perceptions and potential of the advanced practitioner role: a qualitative analysis. BMJ Open 2015;5:e009740.

70 Maier CB, Köppen J, Busse R, et al. Task shifting between physicians and nurses in acute care hospitals: cross-sectional study in nine countries. Hum Resour Health 2018;16:24.

71 Maier CB, Aiken LH. Task shifting from physicians to nurses in primary care in 39 countries: a cross-country comparative study. Eur $J$ Public Health 2016;26:927-34.

72 Peters M, Godfrey C, Mclnerney P, et al. JBI reviewer's manual, chapter 11: Scoping reviews: the Joanna Briggs Institute;. Available: https://reviewersmanual.joannabriggs.org/ [Accessed 17 Oct 2019].

73 Peters MDJ, Godfrey CM, Khalil H, et al. Guidance for conducting systematic scoping reviews. Int J Evid Based Healthc 2015;13:141-6.

74 Arksey H, O'Malley L. Scoping studies: towards a methodological framework. Int J Soc Res Methodol 2005;8:19-32.

75 Levac D, Colquhoun H, O'Brien KK. Scoping studies: advancing the methodology. Implement Sci 2010;5:69.
76 Tricco AC, Lillie E, Zarin W, et al. PRISMA extension for scoping reviews (PRISMA-ScR): checklist and explanation. Ann Intern Med 2018;169:467-73.

77 Evans C, Poku B, Pearce R, et al. Characterising the evidence base for advanced clinical practice in the UK: a scoping review: open science framework (registries), 2019. Available: https://osf.io/tzpe5 [Accessed 06 Nov 2019].

78 Olaussen A, Semple W, Oteir A, et al. Paramedic literature search filters: optimised for clinicians and academics. BMC Med Inform Decis Mak 2017;17:146-46.

79 Ayiku L, Levay P, Hudson T, et al. The Medline UK filter: development and validation of a geographic search filter to retrieve research about the UK from OVID Medline. Health Info Libr J 2017;34:200-16.

80 Ayiku L, Levay P, Hudson T, et al. The Embase UK filter: validation of a geographic search filter to retrieve research about the UK from OVID Embase. Health Info Libr J 2019;36:121-33.

81 Moher D, Liberati A, Tetzlaff J, et al. Preferred reporting items for systematic reviews and meta-analyses: the PRISMA statement. $J$ Clin Epidemiol 2009;62:1006-12.

82 Bryant-Lukosius D, Callens B, De Geest S, et al. Advanced nursing practice roles in Switzerland: a proposed framework for evaluation. Basel, Switzerland: Institute of Nursing Science, University of Basel, 2015.

83 Bryant-Lukosius D, Spichiger E, Martin J, et al. Framework for evaluating the impact of advanced practice nursing roles. J Nurs Scholarsh 2016;48:201-9.

84 Donabedian A. Evaluating the quality of medical care. Milbank Mem Fund Q 1966;44:166-203.

85 Carroll C, Booth A, Leaviss J, et al. "Best fit" framework synthesis: refining the method. BMC Med Res Methodol 2013;13:13-37.

86 QSR. NVIVO 12 pro. Available: https://www.qsrinternational.com/ nvivo/nvivo-products/nvivo-12-pro [Accessed 13 Feb 2020]

87 Preston L, Chambers D, Campbell F, et al. What evidence is there for the identification and management of frail older people in the emergency department? A systematic mapping review. Health Serv Deliv Res 2018;6:1-142.

88 Schønning V, Aarø LE, Skogen JC. Central themes, core concepts and knowledge gaps concerning social media use, and mental health and well-being among adolescents: a protocol of a scoping review of published literature. BMJ Open 2020;10:e031105.

89 Joanna Briggs Institute. JBI levels of evidence. Available: https:// joannabriggs.org/jbi-approach.html\#tabbed-nav=Levels-of-Evidence [Accessed 17 Oct 2019].

90 Popay J, Roberts H, Sowden A. Guidance on the conduct of narrative synthesis in systematic reviews: a product from the ESRC methods programme version. Lancaster University, 2006.

91 Booth A, Mshelia S, Analo CV, et al. Qualitative evidence syntheses: assessing the relative contributions of multi-context and singlecontext reviews. J Adv Nurs 2019;75:3812-22.

92 Hannes K, Harden A. Multi-context versus context-specific qualitative evidence syntheses: combining the best of both. Res Synth Methods 2011;2:271-8.

93 Courtenay M, Carey N, Burke J. Independent extended and supplementary nurse prescribing practice in the UK: a national questionnaire survey. Int J Nurs Stud 2007;44:1093-101.

94 Department of Health. Modernising nursing careers: setting the direction. Edinburgh: Scottish Executive, 2006.

95 Scottish Government. Supporting the development of advanced nursing practice: a toolkit approach. Edinburgh: CNO Directorate, 2008.

96 The Royal Pharmaceutical Society. Advanced pharmacy framework. London: Royal Pharmaceutical Society Faculty, 2013.

97 Meadows N, Webb D, McRobbie D, et al. Developing and validating a competency framework for advanced pharmacy practice. Pharm $J$ 2004;273:789-92.

98 Academy Health. Health services research and health policy grey literature project: summary report, 2006. Available: http://wayback. archive-it.org/org-350/20091118142451/http://www.nlm.nih.gov/ nichsr/greylitreport_06.html [Accessed 14 Feb 2020]. 